OPEN ACCESS

\section{Convective origin of stratospheric water vapor?}

To cite this article: Johannes K Nielsen et al 2009 IOP Conf. Ser.: Earth Environ. Sci. 6092021

View the article online for updates and enhancements.

\section{Related content}

The Vertical Component of the Superaranular Motion T. L. Duvall, Jr. and A. C. Birch

- Supergranulation as the Largest Buoyantly Driven Convective Scale of the Sun Jean-Francois Cossette and Mark P. Rast

- The Spectrum of the Solar

Supergranulation: Multiple Nonwave Components

Mark P. Rast, Jason P. Lisle and Juri Toomre 
P09.09

Convective origin of stratospheric water vapor?

Johannes K Nielsen(1), N Larsen(1), T Christensen(1), S Khaykin(2), J-P Pommereau(3)

(1) Danish Meteorological Institute, Denmark

(2) Central Aerological Observatory, Russia

(3) CNRS, France

In the general circulation pattern of the Earth's atmosphere, air enters the stratosphere from the troposphere mainly through the tropical tropopause (Brewer, A. M., Quart. J. Royal Meteorol. Soc.,(1949), 75, 351-363). In spite of its diluteness, stratospheric water vapor plays important roles both in the radiation budget and in the chemistry of the Earth's atmosphere. Increase of stratospheric water in the late 20'th century has earlier been estimated to cause a radiative forcing of up to $40 \%$ of the forcing due to well mixed greenhouse gases (Forster, P. M. d. \& Shine, K. P, Geophys. Res. Lett., (2002), 29, 10-1), but a recent reevaluation of the stratospheric water vapor climatology implies that this is probably an overestimate (Scherer, M., Atmos. Chem. Phys.,(2008), 8, 1391-1402). Predictability of stratospheric water vapor is nevertheless of great importance for modelling future climate. Long term variations of stratospheric water vapor abundance are controlled by poorly understood cloud processes in ascending air near the tropical tropopause. Therefore, understanding of microphysical processes in clouds near the tropical tropopause is important for climate modelling. In situ measurements have uncovered unexpected thermodynamic behaviors of cirrus ice particles, such as supersaturation of gas phase water vapor with respect to ice inside clouds, and long lived solid particles in the lower tropical stratosphere (Nielsen, J. K. et al., Atmos. Chem. Phys. (2007), 7, 685695). In this presentation we report balloon-borne combined optical particle and humidity in situ measurements from tropical West Africa, showing that solid particles coexist with air, subsaturated with respect to ice in the lowest stratosphere in the vicinity of thunderstorms, and we propose a theoretical explanation of this finding. Several observations of enhanced water vapor mixing ratios and presence of particles above the tropical tropopause is building up evidence for transport of water vapor to the stratosphere by overshooting tropical thunderstorms. If tropical thunderstorms are substantially contributing to transport of water from the troposphere to the stratosphere then this physical process needs to be represented in climate models. 